\title{
PERANAN VIDEO YOUTUBE SEBAGAI ALTERNATIF MEDIA PEMBELAJARAN DI MASAPA PANDEMI
}

\author{
Nurul Magfirah \\ Prodi Pendidikan Biologi, FKIP, Universitas Muhammadiyah Makassar, Indonesia
}

nurul.magfirah@unismuh.ac.id ${ }^{1)}$

\begin{abstract}
Abstrak
Penelitian ini memiliki tuajuan untuk mengetahui apakah ada pengaruh media video youtube terhadap hasil belajar IPA siswa SMP Negeri 2 Sungguminasa kabupaten Gowa, dimana metode pada penelitian ini yaitu jenis penelitian Quasi Eksperimen, dengan desain penelitian One group Pretest-Postest, pada penelitian ini tes dilakukan sebanyak 2 kali, yaitu tes awal sebelum perlakuan, kemudian pemberian perlakuan, selanjutnya tes akhir yaitu tes yang dilakukan setelah perlakuan. Populasi pada penelitian ini yaitu seluruh kelas VIII tahun pelajaran 2020-2021 SMP Negeri 2 Sungguminasa Kabupaten Gowa yang terdiri dari 371 dan sampel penelitian terdiri dari 33 siswa. Hasil penelitian berdasarkan hasil analisis data pada uji hipotesis dengan menggunakan uji paired $t$ test diperoleh nilai rata-rata pada pada pretest yaitu 49,94 dan nilai posttest yaitu 76,70. Sedangkan nilai Sig sebesar 0,000 dengan taraf signifikansi $(\alpha)$ adalah 0,05 , hal ini menunjukan bahwa nilai Sig lebih kecil dari taraf signifikasi $(\alpha)$ sehingga kesimpulan dalam penelitian ini adalah ada peningkatan hasil belajar siswa yang di ajar dengan menggunakan media video youtube pada pembelajaran daring pada siswa kelas VIII SMP Negeri 2 Sungguminasa Kabupaten Gowa.
\end{abstract}

Kata Kunci: Pembelajaran Daring, Video Youtube, Hasil Belajar.

Published by:

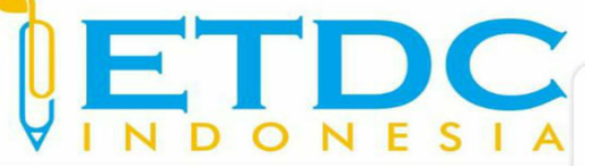

Copyright (C) 2021 The Author (s)

This article is licensed under CC BY 4.0 License

$(\mathrm{cc})$ BY 


\section{PERANAN VIDEO YOUTUBE SEBAGAI ALTERNATIF MEDIA PEMBELAJARAN DI MASAPA PANDEMI}

\section{Pendahuluan}

Pandemi covid-19 mulai masuk ke Indonesia sejak awal tahun 2020. Menyebabkan krisis Kesehatan yang tidak hanya terjadi di indonesi tetapi terjadi di penjuru dunia, selaian krisis Kesehatan akibat pandemi ini juga berdampak pada kegiatan ekonomi yang turut ikut melemah. Selain itu dampaknya juga dirasakan oleh dunia Pendidikan. Hal tersebut juga dikemukakan (Handarini \& Wulandari, 2020) bahwa Perserikatan Bangsa-Bangsa (PBB) menyebutkan bahwa dunia Pendidikan juga menjadi salah satu yang terdampak akibat adanya wabah covid-19.

Peristiwa tersebut menjadi perhatian yang sangat serius bagi pemerintah. Sehingga menganjurkan kepada seluruh masyarakat untuk menghentikan kegiatan yang dapat menyebabkan perkerumunan sebagai upaya untuk memutus rantai penularan covid-19. Salah satunya yaitu dengan menutup sementara sekolah dan juga perguruan tinggi. Kemendikbud dalam surat edarannya meminta untuk melaksanakan pembelajaran jarak jauh melalui pebelajaran daring dari rumah masing-masing. Pembelajaran daring merupakan pembelajaran yang menggunakan flatform dalam proses pembelajaran, sehingga pembelajaran tidak dilaksanakan dengan tatap muka langsung (Handarini \& Wulandari, 2020).

Pembelajaran yang dilaksanakan secara daring menjadi satu-satunya solusi yang di anggap paling aman agar proses belajar mengajar tetap terlakasana selama pendemi. Meskipun tidak seefektif dengan pembelajaran tatap muka disekolah. Hal tersebut disebabkan karena pada awal pandemi baik guru maupun siswa mamiliki persiapan yang sangat kurang untuk pelasanaan pembelajaran daring. Menurut (Fauzy \& Nurfauziah, 2021) Pandemi covid-19 yang muncul secara mendadak mdenyebabkan para siswa kurang siap dalam pelaksanaan pembelajaran daring.

Berdasarkan hasil wawancara pada guru mata pelajatan IPA SMP Negeri 2 Sungguminasa Kabupaten Gowa, bahwa pada awal pandemi covid-19 pembelajaran daring dilaksanakan dengan cara memberikan materi dan tugas kepada siswa melalui aplikasi Group Whattshap. Dimana siswa diminta untuk membaca sendiri materi kemudian mengerjakan tugas dan disetor melalui whattshap atau kadang juga melalui google classroom. Namun banyak siswa yang tidak berminat dan aktif dalam pembelajaran dimana dapat dilihat dari kurang siswa yang menyetor tugas kepada guru.

Sebagai seorang guru perlu memikirkan solusi untuk masalah tersebut. Salah satu upaya 
dilakukan oleh guru IPA SMP Negeri 2 Sungguminasa yaitu memanfaatkan media video youtube sebagai alternatif media pembelajaran dalam pembelajaran daring. Peranan guru dalam pembelajaran dikelas penting karena siswa masih sangat membutuhkan guru sebagai fasilitator dalam memberikan pemahaman kepada siswa terkait dengan mata pelajaran yang dipelajari. Gutu harus mampu berunavatif dan kreatif. Pemanfaatan Vlog YouTube membantu peran guru dalam pembelajaran agar suasana belajar dalam kelas lebih menyenangkan (Karamina et al., 2020)

Selaian karena video youtube banyak menyediakan banyak materi yang sesui dengan materi pelajaran IPA, video youtube juga merukan situs yang banyak diminati oleh siswa. Hal ini sejalan dengan pendapat (Fatmawati et al., 2018) yang menyatakan pendidik sebaiknya diarahkan untuk mencari video-video yang edukatif pada youtube yang sesuai dengan pateri pelajaran, karena video youtube merupakan situs yang diminati oleh banyak siswa. Selain itu menurut (Cahyono \& Hassani, 2019) YouTube bisa digunakan sebagai media penyampai pesan (informasi) berkonten materi pelajaran.

Sehingga dalam penelitian ini diangakat rumusan masalah apakah ada pengaruh media video youtube terhadap hasil belajar siswa SMP Negeri 2 Sungguminasa Gowa selama pembelajaran daring di masa pendemi covid-19”.

\section{Metode Penelitian}

Metode penelitian yang peneliti gunakan pada penelitian ini adalah metode eksperiment, dengan jenis penelitian Eksperiment semu atau biasa disebut dengan Quasi Eksperiment . dikatan demikian karena eksperiment ini belum mengkuti aturan-aturan tertentu sehingga belum dapan dikatakan ilmiah. Dalam penelitian ini hanya variable yang ditentukan yang dapat diukur sementara variable yang berpengaruh lainnya tidak dapat diukur.

Dalam penelitian ini desain penelitian yang digunakan adalah One group PretestPostest, dimana dalam penelitian ini dilakukan tes sebanyak 2 kali pada kelas yang telah ditentukan, yaitu melakukan tes awal kemudian pemberian perlakuan selanjutnya melakukan tes akhir setelah pemberian perlakuan. Populasi dalam penelitian ini adalah seluruh siswa kelas VIII SMP Negeri 2 Sungguminasa Gowa yang terdiri dari 371 Siswa, sampel pada penelitian ini yaitu kelas VIII.1 yang terdiri dari 33 orang siswa, dan tekhnik pengambilan sampel yaitu tekhnik random sampling. Penelitian ini dilaksankan pada semester Genap tahun pajaran 20202021. Variable dalam penelitian ini terdiri atas variable bebas dan variable terikat, dimana variable bebas yaitu media video youtube sedangkan variable terikat adalah hasil belajar.

Pada penelitian ini, Instrumen penelitian yang digunakan adalah instrumen tes yaitu tes 
dalam bentuk soal essai yang terdiri dari 10 nomor berdasarkan indikator capaian hasil belajar siswa. Instrumen tes yang digunakan berupa tes objektif. Sebelum tes di ujikan, terlebih dahulu dikalibirasi instrumen berupa uji validitas instrumen tes, uji reliabilitas instrumen tes, indeks kesukaran instrumen tes, dan daya pembeda instrumen tes dilakukan. Selnjutnya tes tersebut di ujikan pada siswa saat pretest dan posttest.

Data yang diperoleh yaitu data sebelum pemberian perlakuan (preetest) dan data setelah pemberian perlakuan (posttest) kemudian dianalisis dengan menfaatkan program SPSS versi 25.0. tekhnik analisis data dilakukan dengan uji analisis statistik desktiktif dan analisis inferensial dengan uji hipotesis menggunakan uji paired t test untuk mengetahui apakah ada pengaruh media video youtube terhadap hasil belajar IPA selama pembelajaran daring.

\section{Hasil dan Pembahasan}

Pelaksanaan penelitian ini menggunakan dua kelas yaitu Kelas XI IPA 1 sebagai kelas eksperimen dengan jumlah siswa 16 orang dan Kelas XI IPA 2 merupakan kelas kontrol dengan jumlah siswa 15 orang. Kedua kelas tersebut diajarkan materi yang sama yaitu materi sistem gerak pada manusia dengan menggunakan model yang berbeda. Dimana kelas eksperimen diberikan perlakuan dengan menerapkan model pembelajaran Student Facilitator And Explaining (SFAE) sedangkan kelas kontrol diterapkan model pembelajaran konvensional atau pembelajaran yang berpusat pada guru.

Penelitian dilakukan pada satu kelas yang terpilih melalui teknik random sampling. Dimana kelas tersebut diberikan perlakuan dengan memanfaatkan video youtube sebagai alat bantu penyampaian pengetahuan dalam pembelajaran daring. Data yang diperoleh sebagai hasil penelitian ini yaitu hasil pretest dan posttest yang dianalisis statistik deskriptif diperoleh nilai rata rata post-test lebih besar dari rata-rata nilai preetest.

Berikut adalah Tabel 1. hasil analisis statistik desktiptif dan inferensial:

Tabel 1. Data statistik deskrptif hasil belajar IPA kelas eksperimen

\begin{tabular}{ccc}
\hline Statistik & \multicolumn{2}{c}{ Kelas Eksperimen } \\
\cline { 2 - 3 } Deskriptif & Pretast & Posttest \\
\hline Skor terendah & 35 & 55 \\
Skor tertinggi & 65 & 91 \\
Rata-rata & 49,94 & 76,70 \\
Standar Deviasi & 7,628 & 9,054 \\
\hline
\end{tabular}


Tabel 2. Distribusi Frekuensi dan Persentasi Nilai Hasil Belajar IPA Sebelum diberikan perlakuan (Pretest) dan Setelah diberikan Perlakuan (Posttest)

\begin{tabular}{lcccccc}
\hline & & \multicolumn{4}{c}{ Kelas Eksperimen } \\
No & $\begin{array}{c}\text { Interval } \\
\text { Nilai }\end{array}$ & Freetest & \multicolumn{2}{c}{ Posttest } & Hasil Belajar \\
\hline 1. & $>80$ & 0 & 0 & 11 & 33,33 & Sangat baik \\
2. & $61-80$ & 2 & 6,06 & 19 & 57,58 & Baik \\
3. & $41-60$ & 27 & 81,82 & 3 & 9,09 & Cukup \\
4. & $21-40$ & 4 & 12,12 & 0 & 0 & Kurang \\
5. & $<20$ & 0 & 0 & 0 & 0 & Sangat Baik \\
\hline & Jumlah & 33 & $100 \%$ & 33 & $100 \%$ & \\
\hline
\end{tabular}

Untuk nilai rata-rata, dimana nilai rata-rata pretest 49,94 dan nilai rata-rata posttest 76,70 , menunjukkan bahwa nilai setalah pemberian perlakuan lebih besar dari pada nilai ratarata sebelum diberikan perlakuan, dengan demikian dapat di simpulkan media youtube terbukti dapat meningkatkan hasil belajar IPA siswa kelas IX SMP Negeri 2 Sungguminasa Gowa.

Sementara untuk uji hipotesis pada penelitian dilakukan dengan menggunakan program SPSS versi 25.0 dengan uji Paired t test. Uji hipotesis yang dilakukan menunjukkan bahwa nilai signifikansi sebesar $0,000 \leq 0,05$. Berdasarkan data tersebut maka dapat dinyatakan bahwa terdapat perbedaan yang nyata antara hasil belajar IPA pada data pretest dan postest, sehingga dari hasil ini dapat kita simpulkan bahwa pembelajaran dengan bantuan media yuoutube dapat meningkatkan hasil belajar IPA siswa kelas IX SMP Negeri 2 Sungguminasa Gowa.

Berdasarkan hasil penelitian dan analisis data, pembelajaran daring dengan bantuan media video youtube. Memberikan pengaruh yang baik terhadap hasil belajar siswa. Hal ini disebabkan karena dengan pemanfaatan video youtube dalam pembelajaran daring, dimana pada pembelajaran ini, guru mengirimkan url video youtube yang sesuai dengan materi kepada siswa melalui aplikasi whattshap dapat membuat siswa lebih tertarik belajar, hal tersebut disebabkan materi pelajaran yang disampaian melalui youtube dirancang demikian kreatifnya agar lebih menarik, dilengakapi penjelasan dengan menggunakan bahasa yang mudah di pahami oleh siswa. Hal ini sejalan dengan pendapat (Mujianto, 2019) yang menyatakan bahwa peserta didik akan lebih tertarik dalam memahami suatu pengetahuan atau teori dengan memanfaatkan youtube. Dengan menggunakan video youtube sebagai media pembelajaran peserta didik dapat dengan cepat memahami materi dibandingkan dengan membaca buku pelajaran, karena media akan dirancang sedemikian rupa agar peserta didik tertarik dan tidak mudah dalam belajar.

Selanjutnya Menurut (Iwantara et al., 2014), Hal yang menaring dalam pembelejaran 
jika menggunakan media video youtube, salah satunya adalah terdapatnya efek teks, efek suara gambar bergerak, yang mengandung instruksi pembelajaran dan animasi didalamnya. Animasi yang disertai instruksi pembelajaran yang dihadirkan dapat memvisualisasikan konsep yang abstrak menjadi lebih nyata sehingga membuat siswa termotivasi untuk belajar. Hal menarik lainnya yang menyebabkan motivasi belajar siswa dengan menggunakan media video youtube lebih tinggi dibandingkan dengan media riil dan media charta karena, bagi beberapa sekolah media video youtube adalah media baru yang interaktif yang sarat dengan Information Teknology (IT) sehingga menimbulkan rasa ingin tahu yang lebih dalam

Selain dari konsep yang menarik yang ada didalam video youtube, kelebihan youtube yang lain yaitu merukan situs yang mudah untuk diaksek, baik itu melalui smartphone, laptop maupun computer. Menurut (Setiawati \& Ekayanti, 2020), proses pembelajaran secara daring lebih praktik dengan menggunakan media video youtube, yaitu dengan hanya menyisipkan URL video yang akan dipilah pada situs Youtube.

Pemanfaatan YouTube sebagai media pembelajaran membantu ketersampaian pesan. Menurut (Pratiwi \& Puspito Hapsari, 2020), salah satu layanan berbagi video di internet yang terpopular saat ini adalah YouTube. YouTube sebagai sebuah situs web video sharing (berbagi video) yang memungkinkan para pengguna menggunggah, mencari video, menonton, diskusi/tanya jawab dan berbagi klip video secara gratis. Video-video tersebut adalah video klip, film, TV, serta video buatan para pengguna.

Situs online yang menjadi video provider di dunia dan paling dominan, selain itu Youtube juga tidak memiliki batasan durasi untuk mengunggah video. Keunggulan lain dari video YouTube yaitu memberikan tawaran layanan tanpa bayar khususnya untuk menikmati dan mengakses video-video yang termasuk dalam sistemnya. Tidak perlu menggunaka akun premium jika ingin mengakses video atau melakukan pembayaran dengan sejumlah uang dalam waktu tertentu. Pengguna YouTube dapat mengunduh beberapa video dan setelah berhasil.

Video youtube merupakan media sosial yang paling banyak peminatnya di kalanyan masyarakat. Diamana berdasarkan data kutipan dari (CNN, 2015) Youtube paling populer diantara kalangan anak muda dewasa, kulit hitam dan Hispanik. Seperti banyak situs jejaring sosial, Youtube banyak digunakan oleh pengguna diantara umur 18 hingga 29 tahun dengan presentase $82 \%$.

Hasil penelitian ini juga sejalan dengan hasil penelitian (Fatmawati et al., 2018), dimana berdasrkan hasil penelitiannya yaitu Rata-rata hasil belajar siswa dengan menggunakan media youtube yaitu 61,78 lebih tinggi daripada ratarata hasil belajar siswa tiding dengan menggunakan media youtube yaitu 59,23. Sehingga disimpulkannya bahwa ada perbedaan hasil belajar kelompok 
siswa yang mengikuti pembelajaran bermedia youtube dengan kelompok siswa yang tidak menggunakan media youtube dalam pembelajaran biologi di SMP Negeri 2 Sungguminasa Gowa.

\section{Kesimpulan}

Berdasarkan hasil penelitian yang diperoleh dengan makukan analisis data melalui uji hipotesis dengan uji paired t test yaitu nilai Sig sebesar 0,000 yang lebih kecil dari nilai tingkat signifikansinya $(\alpha)$ yaitu 0,05 , hal ini menunjukan bahwa nilai Sig lebih kecil dari nilai tingkat signifikasi $(\alpha)$. Maka dapat disimpulkan bahwa ada pengaruh penggunaan media video youtube terhadap hasil belajar IPA siswa kelas VIII SMP Negeri 2 Sungguminasa Kabupaten Gowa dalam pembelajaran daring.

Video youtube merupakan median yang dapat menjadi alat bantu dapam menyampaikan pelajaran kepada siswa, selain merupakan situs yang mudah diakses, media youtube juga merupakan media yang mampu memotivasi belajar siswa karena konsep yang ada dilamnya mampu menarik bagi siswa. Sehingga disarankan untuk memanfaatkan video youtube terkait dengan konten pelajaran sebagai alternatif media pembelajaran yang dapat digunakan selama proses pembelajaran daring berlangsung.

\section{DAFTAR PUSTAKA}

Cahyono, G., \& Hassani, N. (2019). Youtube Seni Komunikasi Dakwah Dan Media Pembelajaran. Al-Hikmah, 13(1), 23. https://doi.org/10.24260/al-hikmah.v13i1.1316

CNN. (2015). YouTube dalam Angka-Angka. https://www.cnnindonesia.com/teknologi/20150214143544-185-32127/youtube-dalamangka-angka

Fatmawati, A., Nofisulastri, N., Adawiyah, S. R., \& Devi, N. S. (2018). Perbedaan Hasil Belajar Siswa Dalam Pembelajaran Biologi Dengan Menggunakan Media Youtube Di Ma Annajah Ponpes Al Halimy Sesela. Bioscientist: Jurnal Ilmiah Biologi, 6(1), 58. https://doi.org/10.33394/bjib.v6i1.2366

Fauzy, A., \& Nurfauziah, P. (2021). Kesulitan Pembelajaran Daring Matematika Pada Masa Pandemi COVID-19 di SMP Muslimin Cililin. Jurnal Cendekia : Jurnal Pendidikan Matematika, 5(1), 551-561. https://doi.org/10.31004/cendekia.v5i1.514

Handarini, O. I., \& Wulandari, S. S. (2020). Pembelajaran Daring Sebagai Upaya Study From Home (SFH). Jurnal Pendidikan Administrasi Perkantoran (JPAP), 8(3), 465-503.an. Jurnal Pendidikan Administrasi Perkantoran (JPAP), 8(3), 465-503.

Iwantara, I., Sadia, I., \& Suma, I. (2014). PENGARUH PENGGUNAAN MEDIA VIDEO YOUTUBE DALAM PEMAHAMAN KONSEP SISWA e-Journal Program Pascasarjana Universitas Pendidikan Ganesha Program Studi IPA Undang-Undang Nomor 20 Tahun 
adalah usaha sa. E-Journal Program Pascasarjana Universitas Pendidikan Ganesha, 4.

Karamina, S., Arsal, T., \& Sunarjan, Y. (2020). The Role of Social Studies Teacher in the Use of YouTube Vlog-Based Learning Media. 443(Iset 2019), 186-190. https://doi.org/10.2991/assehr.k.200620.036

Mujianto, H. (2019). Pemanfaatan Youtube Sebagai Media Ajar Dalam Meningkatkan Minat Dan Motivasi Belajar. Jurnal Komunikasi Hasil Pemikiran Dan Penelitian, 5(1), 135-159. www.journal.uniga.ac.id

Pratiwi, B., \& Puspito Hapsari, K. (2020). Analisis Kemampuan Berpikir Tingkat Tinggi Melalui Pemanfaatan YouTube Sebagai Media Pembelajaran Bahasa Indonesia. Jurnal Ilmiah Sekolah Dasar, 4(2), 282. https://doi.org/10.23887/jisd.v4i2.24238

Setiawati, G. A. D., \& Ekayanti, N. W. (2020). Potret Pembelajaran Menggunakan Whatsapp , Google Classroom, dan Youtube di Masa Pandemi COVID-19. Percepatan Penanganan COVID-19 Berbasis Adat Di Indonesia, 225-230. 